\title{
Biochemical homeostasis and body growth are reliable end points in clinical nutrition trials
}

\author{
William C. Heird \\ Children's Nutrition Research Center, Baylor College of Medicine, 1100 Bates Street, Houston, \\ Texas 77030, USA
}

\begin{abstract}
Studies of biochemical homeostasis and/or body growth have been included as outcome variables in most nutrition trials in paediatric patients. Moreover, these outcome variables have provided important insights into the nutrient requirements of infants and children, and continue to do so. Examples of the value of such studies in improving parenteral nutrition, in defining essential fatty acid metabolism and requirements of infants and in defining the protein and energy needs of low-birth-weight infants are discussed. Data from such studies have helped to define the mechanism of metabolic acidosis and hyperammonaemia associated with the use of early crystalline amino acid mixture and, hence, how to prevent these disorders. Such studies have allowed the development of parenteral amino acid mixtures that circumvent grossly abnormal plasma concentrations of most amino acids and appear to be utilized more efficiently. These studies have also helped define micronutrient requirements, including requirements for several such nutrients that had not been previously recognized as essential (e.g. Cr, Se, Mo, $\alpha$-linolenic acid). Studies of body growth have been particularly valuable in defining the nutritional requirements of low-birth-weight infants. Finally, studies of metabolic homeostasis coupled with more sophisticated metabolic studies have provided considerable insight into the metabolism of the essential fatty acids, linoleic acid (18:2n-6) and $\alpha$-linolenic acid $(18: 3 n-3)$. Although such studies have not defined the amount of the longer-chain PUFA synthesized from each of these essential fatty acids, i.e. arachidonic acid (20:4n-6) and DHA (22:6n-3), they have shown that the rates of conversion are extremely variable from infant to infant, suggesting a possible explanation of why some studies show developmental advantages from intake of these fatty acids while others do not.
\end{abstract}

Biochemical homeostasis: Growth: Total parenteral nutrition: Essential fatty acid metabolism: Preterm and low-birth-weight infants

For decades, biochemical homeostasis and body growth have been among the most commonly included outcome variables of clinical nutrition trials, particularly clinical trials in infants and children. Moreover, data from such studies have contributed immeasurably to the current understanding of a number of nutritional issues. Equally, or perhaps more important, the information obtained from these studies has led to improvements in nutritional management, which in turn have helped decrease both morbidity and mortality. Some of the many contributions of studies of biochemical homeostasis and body growth in clinical nutritional trials are discussed in the present paper. Although not necessarily the most important such contributions, the examples discussed are based largely on the author's studies of biochemical homeostasis and body growth in clinical nutrition trials in paediatric patients. Three examples have been chosen for discussion: (1) the contributions of studies of biochemical homeostasis and body growth to refining and improving parenteral nutrition; (2) the contribution of such studies to the current understanding of essential fatty acid requirements during infancy and childhood; (3) the contribution of these studies to defining nutrient requirements of preterm and low birth weight (LBW) infants.

\section{Contributions of biochemical homeostasis and growth studies to improving parenteral nutrition}

The idea of providing nutrients intravenously to patients with severely compromised gastrointestinal function first 
surfaced just after description of the circulatory system several centuries ago. However, a successful method of delivering nutrients intravenously eluded practitioners until approximately 40 years ago, when Wilmore \& Dudrick (1968) documented normal growth and development of an infant with virtually no remaining small intestine who received only parenterally-administered nutrients for the first several months of life. The breakthrough that made this possible was infusing a concentrated nutrient mixture into a large vein with rapid flow rather than infusing a large volume of a more dilute mixture into a peripheral vein. The components of the nutrient mixture included a protein hydrolysate, glucose, vitamins, some minerals and electrolytes. Although subsequently proven inadequate, periodic infusions of plasma were given as a source of trace minerals and essential fatty acids.

While effective, the therapy was labour-intensive. In addition, as use of the technique spread to other groups of patients, some of the raw materials (e.g. protein hydrolysates) became scarce. Thus, when an inexpensive method for manufacturing crystalline amino acids became available, crystalline amino acid mixtures replaced the protein hydrolysates that had previously been used. Shortly thereafter, metabolic acidosis and hyperammonaemia were noted, particularly in infants and children. In addition, although the crystalline amino acid mixtures provided approximately the same pattern of indispensable amino acids as egg protein, most mixtures contained large amounts of only a few dispensable amino acids (e.g. glycine). Thus, marked derangements of the plasma amino acid pattern of both paediatric and adult patients requiring parenterally-delivered nutrients were common. Finally, despite periodic infusion of a reasonable volume of plasma from normal volunteers, deficiencies of many trace minerals and essential fatty acids were common.

\section{Resolution of metabolic acidosis associated with use of early crystalline amino acid mixtures}

Since metabolic acidosis had not been encountered before the use of crystalline amino acid mixtures, the occurrence of low blood $\mathrm{pH}$, low plasma bicarbonate concentrations and low blood base excess concentrations in the first few subjects receiving parenteral nutrition regimens containing crystalline amino acid mixtures was somewhat surprising (Heird et al. 1972a).

The problem was approached by evaluating the known causes of metabolic acidosis, i.e. excessive gastrointestinal or renal loss of base or intake of actual or potential $\mathrm{H}^{+}$. This exercise documented that neither gastrointestinal nor renal loss of base was greater than expected. For example, stool loss of base, defined as undetermined anion, i.e. the difference between the concentrations of common cations and anions, usually the concentration of $\mathrm{Na}^{+}+\mathrm{K}^{+}-$the concentration of $\mathrm{Cl}^{-}$, was found to be only approximately $0.5 \mathrm{mmol} / \mathrm{kg}$ per $\mathrm{d}$; in comparison, infants with diarrhoea lose four to five times this amount daily (Torres-Pinedo et al. 1966). Renal net acid excretion was actually found to be higher than expected for the extent of metabolic acidosis, indicating that renal base loss also was not excessive. Further, the preformed acid load of the crystalline amino acid mixtures was found to be only approximately $25 \%$ of the preformed acid load, or titratable acidity, of the hydrolysates (10-12 mmol/l v. 30-35 mmol/l).

Comparison of the undetermined anion content of the crystalline amino acids mixtures and the hydrolysates showed that the crystalline amino acid mixtures actually had a 'cation gap' rather than an 'anion gap', i.e. the concentration of $\mathrm{Cl}^{-}$and other anions exceeded the sum of the concentrations of $\mathrm{Na}^{+}$and $\mathrm{K}^{+}$. The protein hydrolysates, on the other hand, had the expected 'anion gap', i.e. $\mathrm{Na}^{+}$and $\mathrm{K}^{+}$concentrations exceeded the concentration of $\mathrm{Cl}^{-}$and other anions. It was further shown that the concentrations of the cationic amino acids (i.e. histidine, arginine and lysine) in the crystalline amino acid mixtures equalled the cation gap. These amino acids, when metabolized in the absence of anionic amino acids, result in release of $\mathrm{H}^{+}$, suggesting, as subsequently shown, that metabolic acidosis could be prevented by addition of anionic amino acids or other organic anions that consume $\mathrm{H}^{+}$when metabolized. Decreasing the cationic amino acid content of the mixture should also be effective, but is not practical because most of these amino acids are indispensable amino acids. A common practice that has been employed since description of metabolic acidosis and its cause is to supply the cationic amino acids as acetate rather than chloride salts so that metabolic acidosis is no longer a problem.

\section{Understanding and preventing hyperammonaemia associated with parenteral nutrition}

The protein hydrolysates that were utilized initially as a $\mathrm{N}$ source for parenteral nutrition regimens contained free $\mathrm{NH}_{3}$ and, hence, resulted in slightly elevated plasma $\mathrm{NH}_{3}$ concentrations (Johnson et al. 1972). However, the $\mathrm{NH}_{3}$ content of these mixtures was less than the amount of $\mathrm{NH}_{4} \mathrm{Cl}$ that was commonly used at that time to treat metabolic acidosis without evidence of hyperammonaemia or other problems. Thus, it was somewhat surprising to encounter a patient who rapidly and unexpectedly became lethargic and developed grand mal seizures after having been maintained uneventfully on a parenteral nutrition regimen containing a crystalline amino acid mixture for approximately 5 weeks (Heird et al. 1972b). The electroencephalogram suggested a 'metabolic disorder' and subsequent evaluation revealed a blood $\mathrm{NH}_{3}$ concentration $>8000 \mu \mathrm{g} / \mathrm{l}$. The amino acid intake was stopped and the blood $\mathrm{NH}_{3}$ concentration was found to drop precipitously to a near-normal value. However, the blood $\mathrm{NH}_{3}$ concentration rose precipitously when the amino acid intake was re-introduced. Administration of supplemental arginine with the crystalline amino acid mixture maintained a normal blood $\mathrm{NH}_{3}$ concentration provided the total arginine intake from both the crystalline amino acid mixture and supplemental arginine was $\geq 1.0 \mathrm{mmol} / \mathrm{kg}$ per $\mathrm{d}$.

Other crystalline amino acid mixtures available at the time contained more arginine and, hence, did not result in metabolic acidosis. As a result of similar findings in a total of three patients, the manufacturer of the culprit crystalline amino acid mixture increased its arginine content and 
symptomatic hyperammonaemia related to the composition of the amino acid infusate has not been observed since.

\section{Improving the composition of parenteral amino acid mixtures}

While the resolution of metabolic acidosis and hyperammonaemia associated with use of crystalline amino acid mixtures resulted in major improvements in the composition of these mixtures, the plasma concentration of many amino acids remained abnormal (Winters et al. 1977). The concentrations of some dispensable amino acids (e.g. glycine) were quite high, as were the concentrations of some indispensable amino acids (e.g. phenylalanine and methionine). These high concentrations were of particular concern among paediatricians because of their experience with inborn errors of metabolism (e.g. phenylketonuria). In these severe conditions the activity of enzymes involved in metabolism of specific amino acids is low, resulting in a high plasma concentration of the specific amino acids. Moreover, these conditions are usually accompanied by severe developmental delays which, although perhaps a coincidence, were assumed to be related directly to the high plasma amino acid concentration. Of equal or greater concern was the fact that the concentrations of other indispensable amino acids (e.g. the branched-chain amino acids, tyrosine and cyst(e)ine) were low. This situation is most probably a reflection of the known relationship between the quality of protein intake and the plasma amino acid pattern. For example, soyabean protein, which has a low methionine content and fails to support normal growth, results in a low plasma concentration of methionine. Both growth and plasma methionine concentration are restored to normal by methionine supplementation of the native protein (Fomon et al. 1979).

The concept of amino acid imbalance, although described only in animals (Harper et al. 1970), cannot be ignored. In this condition the addition of a single amino acid to an otherwise well-balanced-protein diet results in poor growth that is secondary, most probably, to decreased intake.

A mixture of amino acids has been formulated that results in 'normal' plasma concentration of each amino acid (Heird et al. 1987). Tyrosine and cyst(e)ine, both of which are thought to be indispensable amino acids for young infants, are insoluble and/or unstable in aqueous solution; thus, it is impossible to include these amino acids in crystalline amino acid mixtures. For these amino acids the inclusion of their precursors, phenylalanine and methionine, does not result in higher plasma tyrosine and cyst(e)ine concentrations. The mixture does contain some $\mathrm{N}$-acetyl-L-tyrosine but the bioavailability of this soluble tyrosine salt is less than optimal (Heird et al. 1988; Van Goudoever et al. 1994). Moreover, cyst(e)ine can be provided as the $\mathrm{HCl}$ salt, remembering that it is likely to cause metabolic acidosis (Laine et al. 1991). It also can be provided as the poorly-bioavailable $\mathrm{N}$-acetyl-L-cyst(e)ine (Van Goudoever et al. 1994). Dipeptides containing the amino acids are now available and, in theory, should be the ideal source of tyrosine and cyst(e)ine. Preliminary data (Roberts et al. 2001) are promising.
Limited evidence (Helms et al. 1987) suggests that the mixture of crystalline amino acids that results in normal plasma concentrations of most amino acids may be used somewhat more efficiently for anabolism than mixtures that result in a less-normal plasma amino acid pattern (e.g. retention of approximately $78 \% \mathrm{~N}$ intake $v$. approximately $63 \% \mathrm{~N}$ intake).

Compared with historical data, the incidence of total parenteral nutrition cholestasis appears to be lower in the subjects in whom the crystalline amino acid mixture is initially evaluated (Heird et al. 1987). Other studies, however, have shown no real difference in the incidence of total parenteral nutrition cholestasis as a function of the pattern of amino acids infused (Forchiella et al. 1995).

\section{Defining parenteral micronutrient requirements}

As mentioned earlier, the initial assumption that adequate amounts of trace minerals and essential fatty acids could be provided by periodic infusions of normal plasma to subjects requiring parenteral nutrition has not proved to be true. Thus, a number of previously-undescribed micronutrient deficiencies have been described in patients receiving parenteral nutrients exclusively. This information, in turn, has improved the understanding of the role of these nutrients in human nutrition irrespective of the route of nutrient administration. Trace minerals that had not been recognized previously as essential but have been recognized in patients receiving only parenteral nutrients include Cr (Jeejeebhoy et al. 1977), Se (Kien \& Ganther, 1983), and Mo (Abumrad et al. 1981). The development of neurological abnormalities in a child who had received long-term parenteral nutrition without a source of $\alpha$-linolenic acid (18:3n-3) has established this fatty acid as a second essential fatty acid (Holman et al. 1982). Before the availability of acceptable lipid emulsions for use in parenteral nutrition, classical essential fatty acid deficiency with poor growth and scaly skin lesions were common (Friedman et al. 1976). Currently, the issues concerning parenteral lipid requirements no longer concern the need for linoleic acid (18:2n-6) and $18: 3 n-3$ but, rather, the potential need for their longer-chain more-unsaturated metabolites arachidonic acid (20:4n-6) and DHA (22:6n-3). This issue, too, is pertinent to nutrition generally, independent of the route of nutrient delivery, and will be discussed.

\section{Understanding the essential fatty acid needs of infants}

As mentioned earlier, 18:2n-6 and 18:3n-3 are recognized as essential, or indispensable, fatty acids and the requirements for these fatty acids are reasonably well defined. Each of these fatty acids is converted to longer-chain more-unsaturated fatty acids, the most important of which are $20: 4 n-6$, which is synthesized from $18: 2 n-6$, and $22: 6 n-3$, which is synthesized from $18: 3 n-3$. These two long-chain PUFA are the major $n-6$ and $n-3$ fatty acids respectively in the developing brain and 22:6n-3 is highly concentrated in retinal photoreceptor membranes (Martinez,1992). Together with other $n-6$ and $n-3$ long-chain 
PUFA, 20:4n-6 is also a precursor of various series of eicosanoids (Innis, 1991).

The plasma lipid content of 22:6n-3, but not necessarily that of $20: 4 n-6$, is lower in formula-fed $v$. breast-fed infants (Carlson et al. 1986). Since breast milk contains 22:6n-3 and other long-chain PUFA, whereas conventional formulas available at that time did not (Jensen, 1999), it has been assumed by many researchers that $20: 4 n-6$ and $22: 6 n-3$ as well as $18: 2 n-6$ and $18: 3 n-3$ are essential nutrients for infants. On the basis of these assumptions as well as some studies showing that breast-fed infants and infants supplemented with $20: 4 n-6$ and $22: 6 n-3$, particularly the latter, have more optimal visual and neurodevelopmental outcomes (Carlson et al. 1996; Birch et al. 2000; Lauritzen et al. 2001), infant formulas have recently been supplemented with these fatty acids.

Whether infants are capable of endogenous synthesis of 20:4n-6 and $22: 6 n-3$ if given adequate $18: 2 n-6$ and $18: 3 n-3$ remained unknown until the early 1990 s, when it was shown by several investigators that $18: 2 n-6$ and $18: 3 n-3$ labelled with stable isotopes of either $\mathrm{C}$ or $\mathrm{H}$ are converted to the respective long-chain PUFA (Demmelmair et al. 1995; Carnielli et al. 1996; Salem et al. 1996; Sauerwald et al. 1996, 1997). This finding suggests that it might be possible to supply the requirements of these fatty acids by increasing the content of the precursors in formula, particularly that of $18: 3 n-3$, the precursor of $22: 6 n-3$

However, plasma lipid concentrations of $22: 6 n-3$ remain lower than those of breast-fed infants, even in infants receiving a reasonably high intake of $18: 3 n-3$ (Ponder et al. 1992; Jensen et al. 1997). Thus, it appears that endogenous synthesis of $22: 6 n-3$ is not sufficient to maintain the same plasma lipid content of this fatty acid as that observed in subjects who receive a preformed source of $22: 6 n-3$. Nonetheless, it is important to note that not all studies have shown that supplementation of formulas with these fatty acids confers developmental benefits (Lucas \& Morley, 1999; Makrides et al. 2000; Auestad et al. 2001).

Despite the widespread availability of supplemented formulas throughout the world, the role of $22: 6 n-3$ in infant nutrition remains an active area of investigation. Current understanding, based primarily on studies of biochemical homeostasis plus studies of metabolism of labelled precursor fatty acids as well as assessment of visual and neurodevelopmental function, suggests that the rate of conversion of $18: 2 n-6$ and $18: 3 n-3$ to $20: 4 n-6$ and $22: 6 n-3$ respectively varies widely from infant to infant (Carnielli et al. 1996; Salem et al. 1996; Sauerwald et al. 1996). This variation may help to explain some of the apparent discrepancies among studies of long-chain PUFA supplementation on development, some of which show advantages of supplementation and some of which do not.

\section{Contributions of studies of growth in defining protein needs of preterm and low-birth-weight infants}

Growth has long been a major outcome variable of clinical nutrition trials in infants; for example, most studies of treatment of malnourished infants include growth as the major outcome variable. Currently, demonstration of
Table 1. Clinical characteristics of low-birth-weight (LBW) infants participating in studies of protein requirements of LBW infants

\begin{tabular}{lc}
\hline Birth weight $750-1750 \mathrm{~g}\left(\%^{*}\right)$ & 29 \\
$750-1250$ & 39 \\
$1251-1500$ & 32 \\
$1501-1750$ & \\
Gestational age 26-34 weeks $\left(\%^{*}\right)$ & 16 \\
$\quad$ < 30 weeks & 59 \\
$30-32$ weeks & 25 \\
$>32$ weeks & $1-10$ \\
Age at first feeding (d) & 28 \\
Age at full intake $(\mathrm{d})$ & $13-19$ \\
Age when birth weight regained $(\mathrm{d})$ & 75 \\
Respiratory distress $\left(\%{ }^{*}\right)$ & 74 \\
Antibiotic therapy $\left(\%{ }^{\star}\right)$ & 62 \\
Parenteral nutrition $\left(\%^{*}\right)$ & $7-14$ \\
Duration of total parenteral nutrition $(\mathrm{d})$ &
\end{tabular}

*Percentage of the infants participating in the studies.

normal growth is a common requirement for regulatory approval of newly-designed infant formulas. More recently, studies of body composition have been added to studies of growth, providing additional insights into the nutrient needs of infants.

One of the more pressing needs in paediatric nutrition concerns the nutrient requirements of LBW infants. Unlike the term infant, for whom the nutrient requirements can be defined as the amount of each in a reasonable volume of human milk, LBW infants fed human milk do not grow at the same rate as they would had they not been born prematurely (Kashyap et al.1990). Even if all protein, Ca and $\mathrm{Na}$ in a reasonable volume of human milk are absorbed, the intake of these nutrients will remain considerably less than the amount of each that accumulates during the last trimester of gestation (Forbes, 1982).

The fact that LBW infants fed formulas with a higher content of protein and other nutrients grow at a more rapid rate than infants fed human milk was recognized as long as a half century ago (Gordon et al. 1947). Unfortunately, the formula used in this initial study provided a protein intake of $6 \mathrm{~g} / \mathrm{kg}$ perd, or approximately three times the amount provided by the same volume of human milk. Hence, although the infants were found to exhibit higher rates of growth, they had high plasma concentrations of some amino acids, high blood urea-N concentrations and many developed metabolic acidosis. Eventually, it was shown that preterm infants who receive a protein intake of $4 \mathrm{~g} / \mathrm{kg}$ per $\mathrm{d}$ grow as well as those who receive $6 \mathrm{~g} / \mathrm{kg}$ per $\mathrm{d}$ and also appear to tolerate this intake quite well (Davidson et al. 1967). Nonetheless, what is now considered an irrational fear of a moderate protein intake persisted until approximately the early 1990s. In part, this situation reflected the desire to provide the non-nutritional benefits of human milk (e.g. protection against infection and neurodevelopmental advantages) and the belief that the higher protein content of preterm milk (Atkinson et al. 1980) might support both better growth and non-nutritional benefits.

During the 1980s and early 1990s a number of protein intakes were studied, ranging from $2 \cdot 25 \mathrm{~g} / \mathrm{kg}$ per $\mathrm{d}$ to approximately $4.5 \mathrm{~g} / \mathrm{kg}$ per $\mathrm{d}$, all with a concomitant 
energy intake of approximately $504 \mathrm{~kJ}(120 \mathrm{kcal}) / \mathrm{kg}$ per d (Kashyap et al. 1986, 1988, 1990, 1994). The clinical characteristics of the $>200$ infants enrolled in these studies are summarized in Table 1. Across this range of protein intakes a direct relationship was found between protein intake and weight gain as well as $\mathrm{N}$ balance, plasma concentrations of albumin and transthyretin, and blood urea-N concentration (Kashyap \& Heird, 1994). It was also found that the intrauterine rate of weight gain could be achieved with a protein intake of $2 \cdot 8-3.0 \mathrm{~g} / \mathrm{kg}$ per d. An intake in this range was also shown to support the intrauterine rate of $\mathrm{N}$ retention, while a higher intake was required to maintain normal plasma albumen and transthyretin concentrations. Even at the highest protein intake studied blood urea-N concentrations did not exceed $100 \mathrm{mg} / \mathrm{l}$. Finally, the plasma concentration of most amino acids were found to remain within 2 SD of the concentration observed $2 \mathrm{~h}$ postprandially in normally-growing 30-dold breast-fed term infants (Wu et al. 1986).

Formulas designed specifically for preterm and LBW infants have been available for approximately the last 25 years. Studies by other researchers have shown that infants who receive these formulas $v$. a standard term formula during initial hospitalization perform better on standard developmental tests at 18 months as well as at 7-8 years of age (Lucas, 1999). Although the formulas provide more of several nutrients other than protein, this advantage is usually attributed to the protein content.

Despite the availability of these special formulas for preterm and LBW infants and their obvious advantages over standard term formula, most preterm and LBW infants continue to grow at a slower rate than the fetus in utero. Recent data from the National Institute of Child Health Neonatal Network Centers document that $>90 \%$ of such infants weigh <10th percentile of intrauterine standards at discharge (Ehrenkrantz et al. 1999). Moreover, although there are no firm data showing that this growth pattern is associated with neurodevelopmental delays, there is a growing consensus that such delays occur. Certainly, preterm and LBW infants have a high incidence of both developmental and growth delays (Saigal et al. 2001). However, the neurodevelopmental delays may not be a consequence of their poor early growth secondary to inadequate nutrient intake but, rather, a consequence of a myriad of other factors to which they are subjected during their frequently long initial hospital stays. Of these possibilities, it is far easier to improve nutrient intake than control the many non-nutritional factors. Thus, doing so seems wise.

Irrespective of the contribution of poor nutrition and growth to the long-term neurodevelopmental deficits of preterm and LBW infants, it is clear that growth will continue to be an important outcome variable of studies for defining optimal growth and optimal nutrient intakes of these vulnerable infants.

A major problem appears to be the fact that currentlyavailable formulas, although supporting normal growth and some catch-up growth once full intakes are achieved, do not support sufficient growth to allow the infant to overcome the deficits often encountered during the first several days to few weeks of life when nutrient intake is inadequate (Heird, 1999, 2001). Interestingly, the recently introduced 'post-discharge formulas', which have a higher protein and a slightly higher energy content, support growth at rates in excess of that supported by term formulas, and infants fed these formulas are both somewhat heavier and somewhat longer at 18 months of age. However, these formulas do not appear to support greater rates of growth than term infant formulas beyond approximately 2-4 months post term (Cooke et al. 1998, 2001; Carver et al. 2001; Lucas et al. 2001).

\section{References}

Abumrad NN, Schneider AJ, Steel D \& Rogers LS (1981) Amino acid intolerance during prolonged total parenteral nutrition reversed by molybdate therapy. American Journal of Clinical Nutrition 34, 2551-2559.

Atkinson SE, Anderson GH \& Bryan MH (1980) Human milk: comparison of the nitrogen composition in milk from mothers of premature and full-term infants. American Journal of Clinical Nutrition 33, 811-815.

Auestad N, Halter R, Hall RT, Blatter M, Bogle ML, Burks W et al. (2001) Growth and development in term infants fed long-chain polyunsaturated fatty acids: A double-masked, randomized, parallel, prospective, multivariate study. Pediatrics 108, 372-381.

Birch EE, Garfield S, Hoffman DR, Uauy R \& Birch DG (2000) A randomized controlled trial of early dietary supply of longchain polyunsaturated fatty acids and mental development in term infants. Developmental Medicine and Child Neurology 42, 174-181.

Carlson SE, Rhodes PG \& Ferguson MG (1986) Docosahexaenoic acid status of preterm infants at birth and following feeding with human milk or formula. American Journal of Clinical Nutrition 44, 798-804.

Carlson SE, Werkman SH \& Tolley EA (1996) Effect of longchain $n-3$ fatty acid supplementation on visual acuity and growth of preterm infants with and without bronchopulmonary dysplasia. American Journal of Clinical Nutrition 63, 687-689.

Carnielli VP, Wattimena DJ, Luijendijk IH, Boerlage A, Degenhart HJ \& Sauer PJ (1996) The very low birth weight premature infant is capable of synthesizing arachidonic and docosahexaenoic acids from linoleic and linolenic acids. Pediatric Research 40, 169-174.

Carver JD, Wu PYK, Hall RT, Ziegler EE, Sosa R, Jacobs J, Baggs G, Auestad N \& Lloyd B (2001) Growth of preterm infants fed nutrient-enriched or term formula after hospital discharge. Pediatrics 107, 683-689.

Cooke RJ, Embleton ND, Griffin IJ, Wells JC \& McCormick KP (2001) Feeding preterm infants after hospital discharge: Growth and development at 18 months of age. Pediatric Research 49, 719-722.

Cooke RJ, Griffin IJ, McCormick K, Wells JCK, Smith JS, Robinson SJ \& Leighton M (1998) Feeding preterm infants after hospital discharge: Effect of dietary manipulation on nutrient intake and growth. Pediatric Research 43, 355-360.

Davidson M, Levine SZ, Bauer CH \& Dann M (1967) Feeding studies in low-birth-weight infants. I. Relationships of dietary protein, fat, and electrolyte to rates of weight gain, clinical courses, and serum chemical concentrations. Journal of Pediatrics 70, 695-713.

Demmelmair H, von Schenck U, Behrendt E, Sauerwald T \& Koletzko B (1995) Estimation of arachidonic acid synthesis in full term neonates using natural variation of ${ }^{13} \mathrm{C}$ content. 
Journal of Pediatric Gastroenterology and Nutrition 21, 31-36.

Ehrenkrantz RA, Younes N, Lemons JA, Fanaroff AA, Donovan EF, Wright LL et al. (1999) Longitudinal growth of hospitalized very low birth weight infants. Pediatrics 104, 280-289.

Fomon SJ, Ziegler EE, Filer LJ Jr, Nelson SE \& Edwards BB (1979) Methionine fortification of a soy protein formula fed to infants. American Journal of Clinical Nutrition 32, $2460-2471$.

Forbes GB (1982) Human milk and the small baby. American Journal of Diseases of Children 136, 577-578.

Forchiella ML, Gura KM, Sandler R \& Lo C (1995) Aminosyn PF or trophamine: which provides more protection from cholestasis associated with total parenteral nutrition? Journal of Pediatric Gastroenterology and Nutrition 21, 374-382.

Friedman Z, Danon A, Stahlman MT \& Oates JA (1976) Rapid onset of essential acid deficiency in the newborn. Pediatrics 58, 640-649.

Gordon HH, Levine SZ \& McNamara H (1947) Feeding of premature infants. A comparison of human and cow's milk. American Journal of Diseases in Children 73, 442-452.

Harper AE, Benevenga NJ \& Wohlhueter RU (1970) Effects of ingestion of disproportionate amounts of amino acids. Physiology Review 50, 428-558.

Heird WC (1999) Early use of parenteral amino acids. In Nutrition of the Very Low Birthweight Infant. Nestle Workshop Series, vol. 43, pp. 53-76 [EE Ziegler, A Lucas and GE Moro, editors]. Philadelphia, PA: Lippincott Williams \& Williams.

Heird WC (2001) Determination of nutritional requirements in pre-term infants with special reference to 'catch-up' growth. Seminars in Neonatology 6, 365-375.

Heird WC, Dell RB, Driscoll JM Jr, Grebin B \& Winters RW (1972a) Metabolic acidosis resulting from intravenous alimentation mixtures containing synthetic amino acids. New England Journal of Medicine 287, 943-948.

Heird WC, Dell RB, Helms RA, Greene HL, Ament ME, Karma P \& Storm MC (1987) Amino acid mixture designed to maintain normal plasma amino acid patterns in infants and children requiring parenteral nutrition. Pediatrics 80, 401-408.

Heird WC, Hay W, Helms RA, Storm MC, Kashyap S \& Dell RB (1988) Pediatric parenteral amino acid mixture in low birth weight infants. Pediatrics 81, 41-50.

Heird WC, Nicholson JF, Driscoll JM Jr, Schullinger JN \& Winters RW (1972b) Hyperammonemia resulting from intravenous alimentation using a mixture of synthetic l-amino acids: a preliminary report. Journal of Pediatrics 81, $162-165$.

Helms RA, Christensen ML, Mauer EC \& Storm MC (1987) Comparison of a pediatric versus standard amino acid formulation in preterm neonates requiring parenteral nutrition. Journal of Pediatrics 110, 466-472.

Holman RT, Johnson SB \& Hatch RF (1982) A case of human linolenic acid deficiency involving neurological abnormalities. American Journal of Clinical Nutrition 35, 617-623.

Innis SM (1991) Essential fatty acids in growth and development. Progress in Lipid Research 30, 39-103.

Jeejeebhoy KN, Chu RC, Marliss EB, Greenberg GR \& BruceRobertson A (1977) Chromium deficiency, glucose intolerance, and neuropathy reversed by chromium supplementation, in a patient receiving long-term total parenteral nutrition. American Journal of Clinical Nutrition 30, 531-538.

Jensen CL, Prager TC, Fraley JK, Chen H, Anderson RE \& Heird WC (1997) Effect of dietary linoleic/alpha-linolenic acid ratio on growth and visual function of term infants. Journal of Pediatrics 131, 200-209.

Jensen RG (1999) Lipids in human milk. Lipids 34, 1243-1271.
Johnson JD, Albritton WL \& Sunshine P (1972) Hyperammonemia accompanying parenteral nutrition in newborn infants. Journal of Pediatrics 81, 154-161.

Kashyap S, Forsyth M, Zucker C, Ramakrishnan R, Dell RB \& Heird WC (1986) Effects of varying protein and energy intakes on growth and metabolic response in low birth weight infants. Journal of Pediatrics 108, 955-963.

Kashyap S \& Heird WC (1994) Protein requirements of low birthweight, very low birthweight, and small for gestational age infants. In Protein Metabolism During Infancy. Nestlé Nutrition Workshop Series, vol. 33, pp. 133-151 [NCR Raiha, editor]. New York: Nestlé Ltd, Raven Press.

Kashyap S, Schulze KF, Forsyth M, Dell RB, Ramakrishnan R \& Heird WC (1990) Growth, nutrient retention, and metabolic response of low-birth-weight infants fed supplemented and unsupplemented preterm human milk. American Journal of Clinical Nutrition 52, 254-262.

Kashyap S, Schulze KF, Forsyth M, Zucker C, Dell RB, Ramakrishnan R \& Heird WC (1988) Growth, nutrient retention and metabolic response in low birth weight infants fed varying intakes of protein and energy. Journal of Pediatrics 113, 713-721.

Kashyap S, Schulze KF, Ramakrishnan R, Dell RB \& Heird WC (1994) Evaluation of a mathematical model for predicting the relationship between protein and energy intakes of low-birthweight infants and the rate and composition of weight gain. Pediatric Research 35, 704-712.

Kien CL \& Ganther HE (1983) Manifestations of chronic selenium deficiency in a child receiving total parenteral nutrition. American Journal of Clinical Nutrition 37, 319-328.

Laine L, Shulman RJ, Pitre D, Lifschitz CH \& Adams J (1991) Cysteine usage increases the need for acetate in neonates who receive total parenteral nutrition. American Journal of Clinical Nutrition 54, 565-567.

Lauritzen L, Hansen HS, Jorgensen MH \& Michaelsen KF (2001) The essentiality of long chain $n-3$ fatty acids in relation to development and function of the brain and retina. Progress in Lipid Research 40, 1-94.

Lucas A (1999) Early nutrition and later outcome. In Nutrition of the Very Low Birthweight Infant. Nestle Workshop Series, vol. 43, pp. 1-13 [EE Ziegler, A Lucas and GE Moro, editors]. Philadelphia, PA: Lippincott Williams \& Williams.

Lucas A, Fewtrell MS, Morley R, Singhal A, Abbott RA, Isaacs E, Stephenson T, MacFadyen UM \& Clements H (2001) Randomized trial of nutrient-enriched formula versus standard formula for postdischarge preterm infants. Pediatrics 108, 703-711.

Lucas A \& Morley R (1999) Efficacy and safety of long-chain polyunsaturated fatty acid supplementation of infant-formula milk: a randomised trial. Lancet 354, 1948-1954.

Makrides M, Neumann MA, Simmer K \& Gibson RA (2000) A critical appraisal of the role of dietary long-chain polyunsaturated fatty acids on neural indices of term infants: a randomized, controlled trial. Pediatrics 105, 32-38.

Martinez M (1992) Tissue levels of polyunsaturated fatty acids during early human development. Journal of Pediatrics 120, S129-S138.

Ponder DL, Innis SM, Benson JD \& Siegman JS (1992) Docosahexaenoic acid status of term infants fed breast milk or infant formula containing soy oil or corn oil. Pediatric Research 32, 683-688.

Roberts SA, Ball RO, Moore AM, Filler RM \& Pencharz PB (2001) The effect of graded intake of glycl-L-tyrosine on phenylalanine and tyrosine metabolism in parenterally fed neonates with an estimation of tyrosine requirement. Pediatric Research 49, 111-119. 
Saigal S, Stoskopf BL, Streimer DL \& Burrows E (2001) Physical growth and current health status of infants who were of extremely low birth weight and controls at adolescence. Pediatrics 108, 407-415.

Salem N Jr, Wegher B, Mena P \& Uauy R (1996) Arachidonic and docosahexaenoic acids are biosynthesized from their 18 -carbon precursors in human infants. Proceedings of the National Academy of Sciences USA 93, 49-54.

Sauerwald T, Hachey DL, Jensen CL, Chen H, Anderson RE \& Heird WC (1996) Effect of dietary $\alpha$-linolenic acid intake on incorporation of docosahexaenoic and arachidonic acids into plasma phospholipids of term infants. Lipids 31, S131-S135.

Sauerwald TU, Hachey DL, Jensen CL, Chen H, Anderson RE \& Heird WC (1997) Intermediates in endogenous synthesis of $\mathrm{C} 22: 6 \omega 3$ and $\mathrm{C} 20: 4 \omega 6$ by term and preterm infants. Pediatric Research 41, 183-187.

Torres Pinedo R, Lavastida M, Rivera CL, Rodriguez H \& Ortiz A (1966) Studies on infant diarrhea. I. A comparison of the effects of milk feeding and intravenous therapy upon the composition and volume of the stool and urine. Journal of Clinical Investigation 45, 469-480.

Van Goudoever JB, Sulkers EJ \& Timmerman N (1994) Amino acid solutions for premature infants during the first week of life: The role of N-acetyl-L-cysteine and N-acetyl-L-tyrosine. Journal of Parenteral and Enteral Nutrition 18, 404-408.

Wilmore DM \& Dudrick SJ (1968) Growth and development of an infant receiving all nutrients by vein. Journal of the American Medical Association 203, 860-864.

Winters RW, Heird WC, Dell RB \& Nicholson JF (1977) Plasma amino acids in infants receiving parenteral nutrition. In Clinical Nutrition Update: Amino Acids, pp. 147-154 [HL Greene, MA Holliday and HN Munro, editors]. Chicago, IL: American Medical Association.

Wu PYK, Edwards NB \& Storm MC (1986) The plasma amino acid pattern of normal term breast-fed infants. Journal of Pediatrics 109, 347-349. 
https://doi.org/10.1079/PNS2005435 Published online by Cambridge University Press 